\title{
Single Wall Carbon Nanotube Gas Sensors
}

https://doi.org/10.52853/18291171-2021.14.1-74

\author{
V.M. Aroutiounian* \\ Yerevan State University, Yerevan, Armenia \\ *E-mail: kisahar@ysu.am \\ Received 18 March 2021
}

\begin{abstract}
Excellent physical properties of carbon nanotubes (CNTs) are used for manufacturing of many electronic devices. Single wall version of CNTs is promising for detection many important gases including gases exhaled by the organism. The most promising is the realization of gas sensors based on metal oxides doped with CNTs. Application of CNT-based sensors to breathe analysis, properties of the SWCNTs gas sensors with metal nanoparticles and metal oxides and CNTs biosensors are reviewed in this paper.
\end{abstract}

\section{Introduction}

Carbon nanotubes (CNTs) have excellent mechanical and electrical properties. They allow for the use of CNTs in many applications, for example, for a wide range of electronic devices, including logic circuits [1], light-displaying devices [2], batteries [3], and sensors [4-9]. CNTs were discovered about two decades ago [10]. They show a unique structure that can be envisioned as a graphene sheet rolled into tubular structure. CNTs can be either single-walled (i.e., SWCNT) or multi-walled (i.e., MWCNT) depending on the number of a concentric graphitic layers (Fig. 1) [11]. The diameter is typically 1-10nm for SWCNTs whereas it can be varied from 1 to over 100nm for MWCNTs. The length of CNTs can also be varied in a broad range from several nm to over $1 \mathrm{~mm}$. The aspect ratio (length vs. diameter) of CNTs can be larger than $\sim 10^{6}$. CNTs are one of the materials with the highest known mechanical strength. The intrinsic tensile strength and Young's modulus can reach $1 T P a$.

A

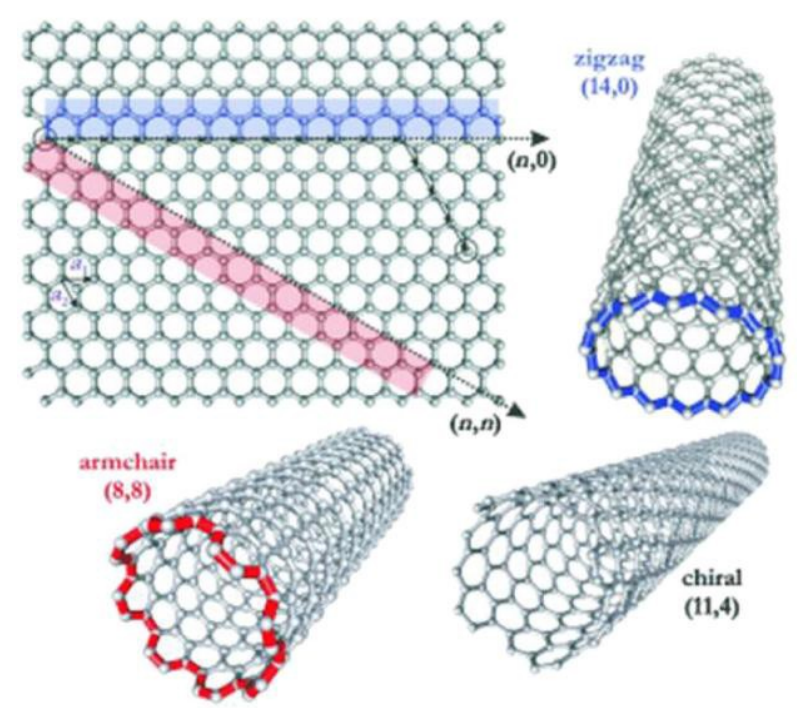

B

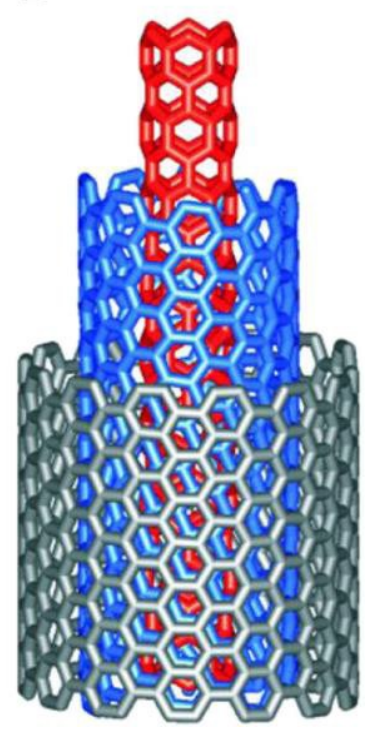

Fig. 1. Depiction of (A) SWCNT with zigzag, armchair and chiral structures, and (B) MWCNT with multiple concentric tubes of graphene [12]. 
Depending on the rolling angle of a graphene sheet (i.e., chirality), CNTs can be either semiconducting or metallic. In their metallic form, CNTs show a very high electrical conductivity with the capability of carrying electrical current over 50 times greater than typical metals. The electrical properties of CNTs are also potentially relevant to biomedical applications. MWCNTs are much less toxic than SWCNTs because of the differences in diameter and surface chemistry.

\section{Detection of gases exhaled by the organism}

Semiconductor sensors very promising for medical applications of gases exhaled by the organism are developed by us in Yerevan State University (Department of Physics of semiconductors and microelectronics and semiconductor research center and the nanotechnology) in Armenia. Acetone, ammonia, benzene, butanol, i-butane, dichlorethane, dimethyl formamide, ethanol, formaldehyde, gasoline, hydrogen, hydrogen peroxide, iperit, methanol, natural gas, nitrogen oxides, propylene glycol, smoke, sulfurous anhydride, sulfurous oxides, toluene, zarin etc. nanosensors should be mentioned among them [4-7]. Warfare chemical sensors were investigated in framework of the NATO grant. Beside experimental works, the structure and defects of metal oxide sensors were investigated using the density functional theory and empirical force fields. The electron density of states was computed. Independent testing of chemical warfare and smoke sensors in the USA and Czech Republic were shown promise of their use.

In particular, large attention is given to sensors made from metal oxides (MOs) doped with CNTs [9, 12-17] which have high sensitivity and other excellent characteristics (see, for example, review-papers [9, 12]). Results of foreign researchers are discussed also in our papers. But properties of SWCNTs and gas sensors based on them did not consider by us.

CNTs are ideal materials for a new class of molecular sensors. CNT-based gas sensors have sensitive chemical-to-electrical transducer capability, high degree of chemical functionality options, and potential for miniaturization. CNTs are widely used for the detection of various gases (including in the human body) and in dentistry, virology and cardiology [18].

Breath analysis is a promising method for rapid, inexpensive, noninvasive disease diagnosis and health monitoring owing to the correlative relationship between breath biomarker concentrations and abnormal health conditions. Breath biomarkers for various diseases are listed in the Table 1 [19-21]. The large experience in YSU in the field of gas semiconductor detectors allows us to make intensive works in this field. For example, we have now the first samples of diabetes detectors which measure the acetone level in an organism [22]. The current challenges and prospective solutions of applying CNT-based sensors to breath analysis are also discussed below.

Table 1. Gases as well as Exhalation and Diagnostic Significance

\begin{tabular}{|l|l|}
\hline Gases & Exhalation and diagnostic significance \\
\hline Nitrogen oxide (NO) & $\begin{array}{l}\text { Respiratory diseases [asthma, chronic obstructive pulmonary disease } \\
\text { (COPD), etc.] Rhinitis digestive diseases [inflammation in the stomach }\end{array}$ \\
\hline
\end{tabular}




\begin{tabular}{|c|c|}
\hline & $\begin{array}{l}\text { (gastritis, hepatitis, colitis), including infection Helicobacter pylon } \\
\text { digestive cancer Hyperthermia Heavy-textured sepsis Uremia }\end{array}$ \\
\hline $\begin{array}{l}\text { Carbon monoxide } \\
(\mathrm{CO})\end{array}$ & $\begin{array}{l}\text { Anemia (hemolytic, sideroblastic cell) Carboxy hemoglobinamija in } \\
\text { acute and chronic exposures Lasting stay at intakes Giperbilirubinonemia } \\
\text { of newborn oxidative stress hematoma Hemoglobinuria Pre-eclampsia of } \\
\text { infection Thalassemia respiratory diseases (asthma, COPD, infections of } \\
\text { the respiratory infection Inflammation of lung) }\end{array}$ \\
\hline Ammonia (NH3) & $\begin{array}{l}\text { Diseases of the kidneys and liver (renal insufficiency in nephritis, } \\
\text { idiopathic hypertension, atherosclerosis of renal artery, toxicosis and } \\
\text { nephropathy of pregnant, toxic defeats of kidneys, paucity of the liver in } \\
\text { jaundice, hepatitis, cirrhosis of the liver, toxic hepatitis) Acute and } \\
\text { chronic radiation sickness The metabolism of monoamine in light Uremia }\end{array}$ \\
\hline Hydrogen $(\mathrm{H} 2)$ & $\begin{array}{l}\text { Diseases of bodies of digestion (digestive disorders of infants } \\
\text { Gastrointestinal Disorders anaerobic bacteria in the large intestine } \\
\text { Malabsorption hydrocarbons) }\end{array}$ \\
\hline $\begin{array}{l}\text { Hydrogen Peroxide } \\
\mathrm{H} 2 \mathrm{O} 2\end{array}$ & $\begin{array}{l}\text { Respiratory diseases (asthma, chronic obstructive pulmonary disease } \\
\text { (COPD), lung cancer, weakened respiratory lung function, etc.) The } \\
\text { acute and chronic radiation sickness Diabetes }\end{array}$ \\
\hline Methane & Diseases of the central nervous system Lung and breast cancer \\
\hline Acetone C6 H6 O & Diabetes \\
\hline Ethanol & $\begin{array}{l}\text { Alcoholism, the function of the pancreas in acute pancreatitis and } \\
\text { execute-destructive dietary and severe balance failure at lung cancer } \\
\text { Diabetes Chronic liver disease }\end{array}$ \\
\hline $\begin{array}{l}\text { Isotopic } \\
\text { modification }\end{array}$ & $\begin{array}{l}\text { Infection with the bacterium Helicobacter pylori passage of food through } \\
\text { the gastrointestinal tract the overgrowth of bacteria lactose Digestion } \\
\text { pancreatic Dysfunction Malabsorption liver dysfunction, including } \\
\text { cirrhosis the metabolism of bile glucose metabolism }\end{array}$ \\
\hline Vapors of urine & Gastroenterology \\
\hline $\begin{array}{l}\text { Pentane and its } \\
\text { Derivatives }\end{array}$ & $\begin{array}{l}\text { Breath and lung cancer. Acute myocardial infarction Heart titrant } \\
\text { rejection Rheumatic arthritis The exacerbation of asthma }\end{array}$ \\
\hline $\begin{array}{l}\text { Alkanes (hexane, } \\
\text { etc.) }\end{array}$ & Lung cancer Tuberculosis \\
\hline $\begin{array}{l}\text { Dimethyl and } \\
\text { carbonyl sulfides }\end{array}$ & $\begin{array}{l}\text { Lung cancer Cystic fibrosis Intra- and extraoral halitosis Chronic liver } \\
\text { disease Hypermethioninemia }\end{array}$ \\
\hline Isoprene & Lung cancer Castaic ulcer Heart failure \\
\hline Hydrogen sulfide & Intraoral halitosis \\
\hline $\begin{array}{l}\text { Heptane, xylenes, } \\
\text { octane, } \\
\text { ethylbenzene, } \\
\text { styrene, decane, } \\
\text { toluene, benzene, } \\
\text { gaseous aldehyde } \\
\text { and formaldehyde }\end{array}$ & Lung cancer \\
\hline
\end{tabular}


It is known that that reducing and oxidizing gases can be detected by metal oxides gas sensors but they require very high operating temperatures and voltages to transduce a detectable electrical response. One solution to this problem is doping of its with CNTs. Semiconducting CNTs in metal oxides are ideal chemical sensing transducers owing to their exceptionally large charge carrier mobility (about $80000 \mathrm{~cm}^{2} \mathrm{~V} / \mathrm{s}$ ) and their nanoscale diameter. In contrast, the electron mobility of metal oxide thin films is three to four orders of magnitude smaller than the mobility of SWCNTs or MWCNTs. Carbon nanomaterial enhancement of gas sensor performance can be due to its direct interaction with the gas analysts. We report below new results about different CNT sensors.

\section{SWCNTs gas sensors with metal nanoparticles and metal oxides}

Metal nanoparticle (NP) /SWCNT gas were showed the sensitivity (response) to $\mathrm{NH}_{3}$, $\mathrm{NO}_{2}, \mathrm{H}_{2}$, and $\mathrm{H}_{2} \mathrm{~S}$ gases (see, for example, [12]). A metal NP with a lower work function can donate many electrons into the valence band of SWCNTs due to the smaller potential barrier. Zanolli et al. investigated the sensing mechanism of gold-decorated CNTs by experimentally measuring the change of the resistance $R$ of this material exposed to different gases $\left(\mathrm{NO}_{2}, \mathrm{CO}, \mathrm{C}_{6} \mathrm{H}_{6}\right)$ and calculated the shift in Fermi level upon exposure of each gas [23]. CNTs were first treated with $\mathrm{O}_{2}$ plasma to create oxygen defects for the purpose of trapping and clustering $A u$ atoms during a thermal evaporation procedure. The Fermi level in the CNT/oxygen defect/ $\mathrm{Au}$ cluster system was calculated when $\mathrm{C}_{6} \mathrm{H}_{6}, \mathrm{CO}$, or $\mathrm{NO}_{2}$ gas molecules were contacted the cluster surface. The Fermi level is increased in the case of $\mathrm{C}_{6} \mathrm{H}_{6}$ and decreased in the case of $\mathrm{NO}_{2}$. For this system, carbon monoxide did not shift the Fermi level. In the chemiresistor measurements, $\mathrm{NO}_{2}$ exposure caused a large increase in $\mathrm{R} . \mathrm{C}_{6} \mathrm{H}_{6}$ exposure did not cause a significant change in $R$, carbon monoxide exposure shows a small increase in $\mathrm{R}$ owing to its large binding energy to gold. The sensitivity and selectivity of metal NP receptors can be tailored to specific gases by controlling the size and elemental identity. Penza et al. investigated the effect of different gold nanocluster sizes sputtered on SWCNTs toward different gases [24]. The sizes of gold nanoclusters chosen were 2.5,5 and 10nm. $P d$ had the largest sensitivity toward $\mathrm{CO}_{2}$. As the affinity gold and sulfur forms $\mathrm{Au} @ S$ bonds, $\mathrm{Au}$ NP/CNTs have been sensitivity to $\mathrm{H}_{2} \mathrm{~S}$ down to $3 \mathrm{ppb} \mathrm{H}_{2} \mathrm{~S}$ [28]. $\mathrm{Au}$ nanowell (NW)/SWCNTs showed superior sensitivity to low concentrations of $\mathrm{H}_{2} \mathrm{~S}$ compared with $\mathrm{Au}$ NP/SWCNT material. To show that this material could be applied to $\mathrm{H}_{2} \mathrm{~S}$ sensing in breath, $\mathrm{H}_{2} \mathrm{~S}$ was successfully detected in an catalytically human breath background of $4 \% \mathrm{CO}_{2} .20 \% \mathrm{O}_{2}$, and saturated "flavor" vapors. 
Note that palladium is is active toward $H @ H$ bond dissociation and is significantly cheaper than platinum [25]. These same properties make $P d$ NPs excellent $H_{2}$ sensor receptors. Mubeen et al. prepared a $\mathrm{H}_{2}$ sensor based on SWCNT networks non-covalently decorated with $P d$ NPs through electrodeposition [26]. Lundstrçm et al. proposed that $H_{2}$ gas molecules adsorbed in air were dissociated into two adsorbed hydrogen atoms on the surface of $P d$ NPs [27]. In the presence of $\mathrm{O}_{2}$, adsorbed $\mathrm{H}$ atoms can react with $\mathrm{O}_{2}$ molecules to produce water molecules. Electron donation from the hydrogen molecules leads to an increase in $R$ proportional to hydrogen concentration. The response of the $P d$ NPs/ SWCNTs network sensed $\mathrm{H}_{2}$ was down to $30 \mathrm{ppm}$. Abdelhalim et al. investigated the role metal identity played toward gas sensitivity by evaporating $A u, A g$, and $P d$ NPs of the same size on CNT films and testing their responses toward four gas molecules $\left(\mathrm{NH}_{3}, \mathrm{CO}, \mathrm{CO}_{2}\right.$, and ethanol) [28]. Au/CNT films showed the largest responses toward $\mathrm{NH}_{3}, \mathrm{CO}$, and ethanol, whereas $\mathrm{Pd}$ had the largest sensitivity toward $\mathrm{CO}_{2}$. Due to the affinity gold and sulfur have to form $A u @ S$ bonds, $A u$ NP/CNTs have been used to sense $H_{2} \mathrm{~S}$ up to down to $3 p p b \quad H_{2} S$ [29] and shown a linear chemiresistor response toward $\mathrm{H}_{2} \mathrm{~S}$ for a dynamic range between 0.2 and $1 \mathrm{ppm}$. Au NW/SWCNTs showed superior sensitivity to low concentrations of $\mathrm{H}_{2} \mathrm{~S}$ compared with $\mathrm{Au}$ NP/SWCNT material. $\mathrm{H}_{2} \mathrm{~S}$ was successfully detected in an expected human breath background of $4 \% \mathrm{CO}_{2}, 20 \% \mathrm{O}_{2}$, and saturated "flavor" vapors [25]. These same properties make $P d$ NPs excellent $H_{2}$ sensor receptors. The SWCNT-Cl defect- $P d$ NP material showed the best sensitivity toward $H_{2}$, with a LOD down to $10 \mathrm{ppm}$ [30].

Gong et al. showed that the incorporation of SWCNTs into a sol-gel-prepared $\mathrm{SnO}_{2}$ film could amplify the sensitivity of $\mathrm{SnO}_{2}$ toward $\mathrm{H}_{2}$ [31]. Quantum effects dominate the sensing mechanism of MO/CNT sensors. In the case of a $\mathrm{SnO}_{2} / \mathrm{SWCNT}$ composite, an $n / p$ junction is created between the $n$-type oxide and the $p$-type $s$-SWCNTs. Upon exposure to $H_{2}$, the potential barrier between the $\mathrm{SnO}_{2}$ grain boundaries is lowered.

Indium tin oxide (ITO) NPs with SWCNT can sense $\mathrm{NHNH}_{3}$ with a limit of detection (LOD) of $13 p p b$ [32]. ITO has p type conductivity at low concentrations of $\mathrm{NH}_{3}$ and humidity; however, at high levels of humidity, it switched to an $n$-type semiconductor through the hole compensation effect of water. Adsorption of $\mathrm{H}_{2} \mathrm{~S}$ molecules on the surface of the $\mathrm{SnO}_{2}$ colloid quantum dots (CQDs) results a sensor response toward $\mathrm{H}_{2} \mathrm{~S}$ down to $3.3 \mathrm{ppm}$. In addition, this composite showed selectivity toward $\mathrm{H}_{2} \mathrm{~S}$ when compared with the responses of $\mathrm{NO}_{2}, \mathrm{NH}_{3}$ and $\mathrm{SO}_{2}$. The $\mathrm{CO}_{3} \mathrm{O}_{4}$ NPs with $4-8 \mathrm{~mm} \mathrm{~nm}$ in diameter can be served as $\mathrm{CO}$ receptors, achieving sensitivity down to $5 \mathrm{ppm}$.

The stability of the receptor's attachment to the transducer is crucial for a reproducible sensor response. In addition, close association between the receptor and transducer is more likely 
to lead to higher electron delocalization. The titanium oxide NPs / SWCNT was sensitive to acetone vapors down to $400 \mathrm{ppb}$ under UV-light. The photoinduced electrons after electron/ hole pair generation in the $\mathrm{TiO}_{2}$ layer are injected into the p-type SWCNT, causing a decrease in conductance and lower current. Acetone adsorption onto $\mathrm{TiO}_{2}$ /SWCNT prevents electron/ hole recombination; thus causing a detectable drop in conductance. The $\mathrm{In}_{2} \mathrm{O}_{2} / \mathrm{SWCNT}$ composite has a greater response towards ethanol than acetone owing to the dissociative adsorption of ethanol on the surface of (111) $\operatorname{In}_{2} \mathrm{O}_{2}$ [33].

Short summary of CNT-based sensors of common breath biomarkers is given below in Table 2.

Table 2. Summary of CNT-based sensors of common breath biomarkers.

\begin{tabular}{|c|c|c|c|c|}
\hline Composite & $\begin{array}{l}\text { Detected } \\
\text { gas }\end{array}$ & $\begin{array}{l}\text { LOD } \\
{[\mathrm{ppm}]}\end{array}$ & $\begin{array}{l}\text { Dynamic } \\
\text { range [ppm] }\end{array}$ & Ref \\
\hline Pd NP/SWCNT & $\mathrm{H}_{2}$ & 100 & $100-1000$ & {$[26]$} \\
\hline $\mathrm{Pd}$ NP/SWCNT & $\mathrm{H}_{2}$ & 30 & $30-10000$ & {$[34]$} \\
\hline $\mathrm{Au}$ NP/SWCNT & $\mathrm{H}_{2} \mathrm{~S}$ & 0.003 & $0.02-1$ & [29] \\
\hline $\mathrm{Au}$ NW/SWCNT & $\mathrm{H}_{2} \mathrm{~S}$ & 0.005 & $0.005-0.5$ & {$[36]$} \\
\hline Ag NC/MWCNT & $\mathrm{NH}_{3}$ & 10 & $10-10000$ & [35] \\
\hline SnO2/SWCNT & $\mathrm{H}_{2}$ & 300 & $300-1500$ & [31] \\
\hline TiO2 /ox-SWCNT & acetone & 0.4 & $2-20$ & {$[36]$} \\
\hline ITO NPs/SWCNT & $\mathrm{NH}_{3}$ & 0.013 & $1-20$ & {$[32]$} \\
\hline Co3O4 / MWCNT & $\mathrm{CO}$ & 5 & $10-700$ & [37] \\
\hline In2O3 /ox-SWCNT & ethanol & 2.5 & $2.5-15$ & [33] \\
\hline $\begin{array}{l}\text { SnO2 QDs / } \\
\text { MWCNT }\end{array}$ & $\mathrm{H}_{2} \mathrm{~S}$ & 0.043 & $3.3-100$ & {$[38]$} \\
\hline CuO/ox-SWCNT & ethanol & 2 & $2-11$ & [39] \\
\hline
\end{tabular}

Rather than detecting a single chemical component at a much higher sensitivity to others, the CNT array (e-nose) approach provides a "fingerprint" for a given compound. Such analysis as linear discriminant analysis (LDA) or principle component analysis (PCA) are commonly used to provide a reproducible detection result from the array output [40]. Kybert et al. studied the use of DNA-functionalized SWCNTs as the sensing element in FET devices for VOC differentiation [41]. Chatterjee et al. replaced DNA with a series of different surfactants to create a chemiresistor array of surfactant-functionalized MWCNTs [42]. An array of these sensors was able to differentiate toluene, chloroform, acetone, ethanol, methanol, and water by using PCA. Haick and co-workers successfully applied the array approach toward discriminating the simulated breath patterns of a healthy subject versus a diseased subject $[43,44]$. The breath investigations of samples of healthy patients and patients with lung cancer were established 15 VOCs that are significant for lung cancer [43]. When a pre-concentration step was used to separate VOCs from humidity, the healthy and cancerous breath patterns could be easily 
distinguished with PCA. Impedance metric sensing of $\mathrm{NH}_{3}$ is less susceptible to drift because it is an AC measurement [45]. An challenge specific to breath analysis is the confounding effect of high levels of humidity on CNT-based sensors. Therefore, removal or separation of humidity is necessary for most trace breath biomarkers. Methods, such as micro-separation columns, membranes, and the use of silica gel have been also proposed to solve the confounding effect of breath humidity on sensor response. Further clinical research into breath biomarkers and their disease correlations, coupled with advances in CNT-based gas sensors, paves the way toward portable, low power, non-invasive, point-of-care breath analysis devices.

Semiconducting SWCNTs devices can be used as a sensor for chemical nerve agents. Thin-film transistors constructed from random networks of SWCNTs were used to detect dimethyl methylphosphonate (DMMP), a simulant for the chemical warfare nerve agent sarin [46]. The devices consist of a lithographically-patterned SWCNT network that bridges $\mathrm{Ti}$ source and drain contacts. The network is grown on the surface of a thermal $\mathrm{SiO}_{2}$ layer, and the $\mathrm{Si}$ substrate serves as a common gate electrode.

These results indicate that the electronic detection of nerve agents and potentially other chemical warfare agents is possible with simple-to-fabricate carbon nanotube devices. Researchers have demonstrated that individual semiconducting SWCNT devices produce a large resistance change in response to certain types of gaseous analytes. In such sensors, the adsorption of an analysts molecule with strong electron donor or acceptor properties results in a partial charge transfer between the analysts and the nanotube that changes its electrical resistance. Autours of [46] found that the electronic properties of the nanotube networks are strongly affected by the presence of DMMP - it readily adsorbs on the SWCNTs, resulting in an effective transfer of negative charge that manifests itself as a shift of the transistor threshold voltage. The molecular adsorption is fully reversible by applying a small positive gate bias that releases the DMMP from the nanotube surface.

The SWCNT-based sensors were reversible and capable of detecting DMMP at sub-ppb concentration levels, and they are intrinsically selective against common interferons. A chemiresistor can detect an exposure to 1 ppb DMMP that was delivered for $3000 \mathrm{~s}$. Sensors are intrinsically selective against interfering signals from hydrocarbon vapors and humidity. Such sensors have detected also $0.1 \mathrm{ppb}$ of $\mathrm{NO}_{2}$, which is superior to current state-of-the-art $\mathrm{NO}_{2}$ sensors by several orders of magnitude. Note that our chemical warfare detectors developed earlier in the framework of the NATO grant are reported in [14].

\section{Carbon nanotubes based biosensors}

CNTs based biosensors can be used in ultra-sensitive and ultra-fast biosensing systems. The basic and some new developed synthetic methods of CNTs are presented in [47]. Note that the concept of CNT-based biosensor was derived from the description of the enzyme electrode by Clark [48]. In general, the CNT-based biosensor includes two parts: biological sensitive element and transducer. The CNT functionalized with biomolecules or bioreceptors, such as proteins, cell receptors, enzymes, antibodies, microorganisms, or even whole biological tissues, which are working as the biological sensitive element [49-51]. The role of transducer is to 
convert the concentration of analysts to other physical signals, such as currents, absorbance, or mass. According to the interactions between analysts and the biological sensitive materials, CNT-based biosensors will be separated into two categories: chemical and physical. Among of them, the CNTs-field effect transistors have superior properties.

The hollow structure of CNTs is good for the adsorption of enzyme. Therefore, CNTs in amperometric CNTs-based biosensors are always used to functionalize with enzyme to generate the enzyme CNT electrodes or to modify the surface of electrodes. CNTs in the CNTFET biosensor configured as FETs offer the advantages of possible biocompatibility, size compatibility, and sensitivity toward minute electrical perturbations for the detection of biological species [51]. They are also low-cost, low-noise and portable [52]. In addition, the effective detect area can be made into the size of a single biomolecules or virus. Because of these unique characteristics, CNTFET biosensor has been widely used in the field of biology, such as protein, glucose, enzyme, antigen and antibody molecules, DNA molecules, bacteria and hormone [53, 54]. In CNTFET biosensor, the preparation of metal electrodes as source and drain electrode are prepared on the surface of silicon substrate coated with silicon dioxide insulating layer. The connection of specific CNTs between the two electrodes is acted as conductive channel, and introducing a gate electrode. The CNTs were synthesized by CVD and the distance between the two electrodes is very small. The specific antibodies can be coated with CNTs, specificity adsorption between antigen and antibody could generate an electric signal that is observed and recorded [51,55]. According to the different reactants, CNTFETs are divided into different types of FET including enzyme FET, immune FET, organization FET, cell FET, and DNAFET. Over the past decade, many groups have brought significant contributions in the development of CNTFET biosensors. For instance, Star et al. [56] prepared nanoscale FET devices with SWCNTs as the conducting channel for the electronic detection of specific protein binding.

Functionalization of CNTs with other nanomaterials, such as polymer, proteins, DNA, enzyme to improve their dispersibility and compatibility with the target biological species [57]. Functionalized CNTs have many improved characteristics, such as large edge plane, high surface activity, high catalytic efficiency and more functional groups. Using the functionalized CNTs can improve the fixed efficiency of biological recognition of molecules (enzymes, DNA, antigen/antibody, etc.) in biosensors (see Table 2 in [47]). Compared with the conventional solid-state carbon biosensors, the biosensors made of functionalized CNTs have higher sensitivity, faster response, and wider detection range. The roles of functionalized CNTs and technologies how to prepare the functionalized CNTs are discussed in very interesting and comprehensive review [47].

Note again that investigations of CNTs look as the most exciting areas in current materials sciences, and the development of CNTs for biomolecule detection is particularly important for bioengineering and biomedical applications. Novel nanotechnologies such as nanoimprint lithography and soft lithography are helpful. Both chemical and physical properties of functionalized CNTs strongly depend on the ambient conditions, such as temperature and $\mathrm{pH}$. Some studies have indicated that the sensitivity and the detection limits is significantly enhanced using nanocomposite materials combine with CNTs and metal ( $A u, P t$, etc.) for biosensor. With the sustainable development of new nanomaterials combined with CNTs, characterization of 
these new materials at the molecular level is essential and a key scientific challenge. In parallel with experimental studies, molecular modeling must be further developed as a tool to predict the performance of new materials for given biomolecules. Such computational methods will enable a quick evaluation of new materials. Clearly, the further development of CNT-based biosensors will allow to fabricate such new micro- /nano-devices as bionanosensors.

Recent developments of novel nanosensors offer promising approaches for improved clinical diagnostics and treatments, with increasing interest in nanomaterials-based biosensors [58-71]. A sensor can include antibodies, aptamers, DNA sequences, molecular imprints, lectins, or synthetic moieties. Various nanoparticles have shown potential to be highly sensitive and selective, such as metal nanoparticles, quantum dots, nanowires, graphene, graphene quantum dots, and carbon nanotubes that can bind and detect biologically relevant concentrations of a target analyst. The use of carbon nanotubes as sensors for biotechnological and biomedical applications is of particular interest [72]. SWCNTs demonstrated long-term stability in vivo [7377].

The non-photo bleaching, non-blinking fluorescent emission of SWCNTs allows using them as optical sensors, enabling in situ, label-free, real-time detection with both spatial and temporal resolution [76-78]. Recent studies have demonstrated the detection of proteins using various approaches for surface functionalization, including natural substrates [79-82] and synthetic polymers [76], with the potential to enable long-term continuous monitoring of important biomarkers or to replace costly and time-consuming laboratory testing [83]. The advantages of SWCNTs for in-vivo and in-vitro biomedical applications such as drug delivery, imaging, and sensing, focusing on protein recognition are investigated. Therefore, the properties of SWCNTs make them excellent candidates for sensing proteins and bio-macromolecules, with optical signal transduction, where advancements in nanotechnology design, synthesis, characterization, and modeling will continue to push forward the discovery of new SWCNTbased fluorescent sensors.

\section{Conclusions}

Excellent physical properties of carbon nanotubes (CNTs) are used for manufacturing of many electronic devices. YSU has large experience in investigations of metal oxide gas sensors doped with MWCNTs. Results of foreign researchers in this field are discussed also in our papers. But properties of SWCNTs and gas sensors based on them did not consider by us. Single wall version of CNTs is promising for detection many important gases including gases exhaled by the organism. The most promising is the realization of gas sensors based on metal oxides doped with CNTs. Application of CNT-based sensors to breath analysis, properties of the SWCNTs gas sensors with metal nanoparticles and metal oxides and CNTs biosensors are reviewed in this paper.

\section{References}

[1] M. L. Geier, P. L. Prabhumirashi, J. J. McMorrow et al. Nano Lett. 2013, 13, 4810.

[2] J. Zou, K. Zhang, J. Li et al. Sci. Rep. 2015, 5, 11755;

[3] Z. Cao, B. B. Q. Wei, Energy Environ. Sci. 2013, 6, 3183.

[4] N. Yang, X. Chen, T. Ren et al. Sens. Actuators B 2015, 207, 690. 
[5] V. M. Aroutiounian In: Dekker Encyclopedia of Nanoscience and Nanotechnol., Second Edition, Taylor and Francis: New York, 2012, p. 1.

[6] V. M. Aroutiounian In: Semiconductor gas sensors, Woodhead Publishing Series in Electronic and Optical Materials N 38, 2013, chapter 12, p. 408.

[7] V. M. Arouriounian Int. J. Hydrogen Energy 32, N 9, p. 1145, 2007.

[8] V. M. Aroutiounian J.Cont. Physics 54, p. 356, 2019.

[9] V. Aroutiounian Armenian J. Phys. 2018, 11, 1, p. 39.

[10] Harris P. Carbon nanotubes and related structures, Cambridge University Press 1999, 279 pp.

[11] E. L. Hopley, Sh. Salmasi, D. M. Kalaskar, A. M. Seifalian Biotechnology Advances 2014.

[12] J. E. Ellis and A.Star Chem Plus Chem 2016, 81, 1248.

[13] Adamyan Z., Aroutiounian V., Sayunts A.et al. Sens. Sens. Syst., 2018, 7, p. 31.

[14] Aroutiounian V. M. Int. Sci. J. Alternative Energy and Ecology, 2018, 249-251, p. 38.

[15] Aroutiounian V. M. Lithuanian J. Phys. 2015, 55, 4, p. 319.

[16] Aroutiounian V. M., V. Arakelyan V.M., Shahnazaryan G.E. Advances in Nano Research 2015, p. 1.

[17] Aroutiounian V. M. Journal of Nanomedicine, Nanotechnology and Nanomaterials, 2020, 1, 1. p. 1.

[18] Aroutiounian V. М. Медицинская наука Армении, 2021(in press).

[19] Aroutiounian V. М. Медицинская наука Армении, 2020, LX, 1, pp. 3.

[20] V. M. Aroutiounian Biomedical J. Sci. \& Tech. Research, 30, 2, p. 23211, 2020

[21] Aroutiounian V. M. Journal of Nanomedicine \& Nanotechnology, 2020, 11, 3, p. 1.

[22] Aroutiounian V.M. J. Cont. Phys. 2021,56, 2 (in press)

[23] Z. Zanolli, R. Leghrib, A. Felten et al ACS Nano 2011, 5, 4592.

[24] M. Penza, R. Rossi, M. Alvisi et al Sens. Actuators B 2009, 140, 176.

[25] M. Shao, J. Power Sources 2011, 196, 2433. [83]

[26] S. Mubeen, T. Zhang, B. Yoo et al J. Phys. Chem. C 2007, 111, 6321

[27] I. Lundstrçm, M. S. Shivaraman, C. Svensson, Surf. Sci. 1977, 64, 497.

[28] A. Abdelhalim, A. Abdellah, G. Scarpa, P. Lugli, Nanotechnology 2014, 25, 055208.

[29] S. Mubeen, T. Zhang, N. Chartuprayoon et al Anal. Chem. 2010, 82, 250;

[30] B. R. Goldsmith, J. G. Coroneus, V. R. Khalap et al Science 2007, 315, 77.

[31] J. Gong, J. Sun, Q. Chen, Sens. Actuators B 2008, 130, 829.

[32] F. Rigoni, G. Drera, S. Pagliara et al Carbon 2014, 80, 356.

[33] J. E. Ellis, U. Green, D. C. Sorescu et al J. Phys. Chem. Lett. 2015, 6, 712.

[34] Y. Sun, H. H. Wang, Adv. Mater. 2007, 19, 2818

[35] S. Cui, H. Pu, G. Lu et al ACS Appl. Mater. Interfaces 2012, 4, 4898.

[36] M. Ding, D. C. Sorescu, A. Star, J. Am. Chem. Soc. 2013, 135, 9015.

[37] L. Dang, G. Zhang, K. Kan et al J. Mater. Chem. A 2014, 2, 4558.

[38] H. Liu, W. Zhang, H. Yu et al ACS Appl. Mater. Interfaces 2016, 8, 840.

[39] G. Peng, S. Wu, J. E. Ellis et al J. Mater. Chem. C 2016, 4, 6575.

[40] P. C. Jurs, G. A. Bakken, H. E. McClelland, Chem. Rev. 2000, 100, 2649.

[41] N. J. Kybert, M. B. Lerner, J. S. Yodh et al ACS Nano 2013, 7, 2800.

[42] S. Chatterjee, M. Castro, J. F. Feller, Sens. Actuators B 2015, 220, 840.

[43] G. Peng, E. Trock, H. Haick, Nano Lett. 2008, 8, 3631.

[44] G. Peng, U. Tisch, H. Haick, Nano Lett. 2009, 9, 1362.

[45] H. P. Hong, J. H. Kim, C. J. Lee, N. K. Min, Sens. Actuators B 2015, 220, 27.

[46] J. P. Novak, E. S. Snow, E. J. Houseret al. APL, 83, 19, ??

[47] N. Yang, X.Chen, T. Ren, et al. Sens. Actuators B 207 (2015) 690.

[48] L.C. Clark, C. Lyons Ann. N. Y. Acad. Sci. 102 (1) (1962) 29.

[49] M. Raicopol, A. Pruna, C. Damian, L. Pilan Nanoscale Res. Lett. 8 (1) (2013) 1-8.

[50] X. Guo Adv. Mater. 25 (25) (2013) 3397-3408.

[51] B.L. Allen, P.D. Kichambare, A. Star Adv. Mater. 19 (11) (2007) 1439-1451. 
[52] D. R. Thévenot, K. Toth, R. A. Durst, G. S. Wilson Biosens. Bioelectron. 16 (1) (2001) 121-131.

[53] H. R. Byon, H. C. Choi J. Am. Chem. Soc. 128 (7) (2006) 2188-2189.

[54] X.W. Tang, S. Bansaruntip, N. Nakayama et al E. Yenilmez, Y.L. Chang, Q. Wang Nano Lett. 6 (8)(2006) $1632-1636$.

[55] M.-J. B. Kim, S. Woo, J. W. Kim et al J. Pharm. Pharmacol.1 (2013) 18-24.

[56] A. Star, J.-C.P. Gabriel, K. Bradley, G. Grüner Nano Lett. 3 (4) (2003) 459-463.

[57] C. Nie, L. Pan, H. Li et al J. Electroanal. Chem. 666 (2012) 85-88.

[58] Anker, J.N.; Hall, W.P.; Lyandres, O. et al In Nanoscience and Technology; Co-Published with Macmillan Publishers Ltd.: London, UK, 2009; pp. 308-319. ISBN 9789814287005.

[59] Farrera, C.; Torres Andón, F.; Feliu ACS Nano 2017, 11, 10637-10643.

[60] Shao, L.; Gao, Y.; Yan, F. Sensors 2011, 11, 11736-11751.

[61] Ramgir, N.S.; Yang, Y.; Zacharias, M. Small 2010, 6, 1705-1722.

[62] Chen, Z.; Zhang, X.; Yang, R et al Nanoscale 2011, 3, 1949.

[63] Liu, Y.; Dong, X.; Chen, P. Chem. Soc. Rev. 2012, 41, 2283.

[64] Shen, J.; Zhu, Y.; Yang, X.; Li Chem. Commun. 2012, 48, 3686-3699.

[65] Gao, C.; Guo, Z.; Liu, J.-H.; Huang, X.-J. Nanoscale 2012, 4, 1948.

[66] Liu, Z.; Tabakman, S.; Welsher, K.; Dai, H. Nano Res. 2009, 2, 85-120.

[67] Yang, W.; Ratinac, K.R.; Ringer, S.R. et al Angew. Chem. Int. Ed. 2010, 49, 2114.

[68] Boghossian, A.A.; Zhang, J.; Barone et al ChemSusChem 2011.

[69] Kim, S.-J.J.; Choi, S.-J.J.; Jang, J.-S.S et al Acc. Chem. Res. 2017, 50, 1587.

[70] Alvarez, M.M.; Aizenberg, J.; Analoui, M. et al ACS Nano 2017, 11, 5195-5214.

[71] Kruss, S.; Hilmer, A.J.; Zhang, J. et al Adv. Drug Deliv. Rev. 2013, 65, 1933.

[72] Eatemadi, A.; Daraee, H.; Karimkhanloo et al Nanoscale Res. Lett. 2014.

[73] Iverson, N.M.; Barone, P.W.; Shandell, M. et al Nat. Nanotechnol. 2013, 8, 873.

[74] Ménard-Moyon, C.; Kostarelos, K.; Prato, M. 2010, 17, 107.

[75] Wu, Y.; Phillips, J.A.; Liu, H.et al ACS Nano 2008, 2, 2023.

[76] Bisker, G.; Dong, J.; Park, H.D. et al Nat. Commun. 2016, 7, 1.

[77] Zhang, J.; Landry, M.P.; Boghossian, A.A. Nat. Nanotechnol. 2013, 8, 959.

[78] Beyene, A.G.; Delevich, K.; Yang, S.J.; Landry, M.P. Biochemistry 2018, 57, 6379.

[79] Dinarvand, M.; Neubert, E.; Meyer et al Nano Lett. 2019, 19, 6604.

[80] Hendler-Neumark A. and Bisker G. Sensors 2019, 19, 5403.

[81] Ahn, J.-H.; Kim, J.-H.; Boghossian, A.A. et al Nano Lett. 2011, 11, 19.

[82] Reuel, N.F.; Ahn J.-H., Boghossian et al J.-H.J. Am. Chem. Soc. 2011, 133, 17923.

[83] Pan, J.; Li, F.; Choi, J.H. J. Mater. Chem. B 2017, 5, 6511. 